\title{
Market interaction and efficient cooperation
}

Citation for published version (APA):

Brandts, J., \& Riedl, A. (2020). Market interaction and efficient cooperation. European Economic Review, 121, [103318]. https://doi.org/10.1016/j.euroecorev.2019.103318

Document status and date:

Published: 01/01/2020

DOI:

10.1016/j.euroecorev.2019.103318

Document Version:

Publisher's PDF, also known as Version of record

Document license:

Taverne

Please check the document version of this publication:

- A submitted manuscript is the version of the article upon submission and before peer-review. There can be important differences between the submitted version and the official published version of record.

People interested in the research are advised to contact the author for the final version of the publication, or visit the DOI to the publisher's website.

- The final author version and the galley proof are versions of the publication after peer review.

- The final published version features the final layout of the paper including the volume, issue and page numbers.

Link to publication

\footnotetext{
General rights rights.

- You may freely distribute the URL identifying the publication in the public portal. please follow below link for the End User Agreement:

www.umlib.nl/taverne-license

Take down policy

If you believe that this document breaches copyright please contact us at:

repository@maastrichtuniversity.nl

providing details and we will investigate your claim.
}

Copyright and moral rights for the publications made accessible in the public portal are retained by the authors and/or other copyright owners and it is a condition of accessing publications that users recognise and abide by the legal requirements associated with these

- Users may download and print one copy of any publication from the public portal for the purpose of private study or research.

- You may not further distribute the material or use it for any profit-making activity or commercial gain

If the publication is distributed under the terms of Article $25 \mathrm{fa}$ of the Dutch Copyright Act, indicated by the "Taverne" license above, 


\title{
Market interaction and efficient cooperation
}

\author{
Jordi Brandts ${ }^{\mathrm{a}, *}$, Arno Riedl ${ }^{\mathrm{b}}$ \\ a Instituto de Analisis Economico (CSIC) and Barcelona GSE, Spain \\ ${ }^{\mathrm{b}}$ Department of Economics (AE1), CESifo, IZA, Netspar, and Maastricht University, P.O. Box 616, Maastricht 6200 MD, the Netherlands
}

\section{A R T I C L E I N F O}

\section{Article history:}

Received 25 May 2018

Accepted 4 September 2019

Available online 13 October 2019

\section{JEL classification:}

A13

C92

D30

D60

Keywords:

Competitive market

Social dilemma

Experiment

\begin{abstract}
A B S T R A C T
We experimentally study causal effects of competitive experience in markets with a short and a long side on efficiency levels attained in a subsequent social dilemma. We find that market experience affects efficiency when traders previously competed in the same market on the same side. The effect is strong for market-loser pairs and also exists for marketwinner pairs, albeit to a lesser extent. Cooperation efficiency is unaffected for pairs consisting of a market-winner and a market-loser. When traders did not interact on the same market before, efficiency of cooperation is higher for market-winner pairs, but only in the short run.
\end{abstract}

(c) 2019 Elsevier B.V. All rights reserved.

\section{Introduction}

Market competition is commonly considered to be a beneficial force and there is no doubt that competitive markets are important for the efficient allocation of resources. This is demonstrated theoretically in the First and Second Welfare Theorems (see, e.g., Mas-Colell et al., 1995) and shown empirically in many field studies and in experiments with double auctions and other competitive market institutions (see, e.g., Smith, 1962; Davis and Holt, 1993). However, an important question is whether the efficiency effects of markets are not circumscribed to the market environment itself but spill over and affect efficiency in other spheres of social and economic interaction. This is especially relevant in relation to interactions through personal exchange where cooperation can not be completely regulated through formal contracts. In this paper we study, using laboratory experiments, whether and how trading experience in a highly competitive market causally affects the efficiency of cooperation in a social dilemma situation outside the market environment. ${ }^{1}$

Competitive market experience can have various facets. A salient feature of modern market societies is that the productive assets - including human capital - are distributed rather unequally (see, e.g., Cowell and Van Kerm, 2015). As a consequence, some people's skills or assets are in high demand in the market, with many others trying to transact with them, while those of others are in much lower demand. Some people may even have difficulties to trade at all (see, e.g., Marquis et al., 2014, for labor markets). Our focus is on whether different market experiences of 'market-winners' and 'market-losers' differentially affect the efficiency of cooperation in social dilemma situations, beyond potential income effects (see, e.g., Bowles, 1998; Smith, 1998, and our more detailed discussion below).

\footnotetext{
* Corresponding author.

E-mail addresses: jordi.brandts@iae.csic.es (J. Brandts), a.riedl@maastrichtuniversity.nl (A. Riedl).

1 Throughout the paper we use the term efficiency of cooperation to refer to the total surplus produced in a social dilemma situation.
} 
Another important aspect that may matter for the efficiency of cooperation in a social dilemma situation outside the market is whether agents are dealing with somebody they have to compete with in the same market or whether competition is experienced with somebody else. It may make a difference whether one has, for example, to supply a local public good jointly with a neighbor who is competing for the same job or customers, or with somebody who is not a direct competitor on the market (see, e.g., Henrich et al., 2001, and our more detailed discussion below). In our study, market interaction takes place in a highly competitive continuous double auction (see Smith, 1962). We use this market institution because it has been shown to consistently converge to the efficient Walrasian outcome and does so through a decentralized equilibrating process in which bids and offers are made and prices and transactions emerge over time (see, e.g., Davis and Holt, 1993). It is the effect on cooperation of having experienced such highly competitive and efficient markets we are interested in. ${ }^{2}$

We designed the experiment in a way that allows us to study the two specific dimensions of spillover effects introduced above. First, we can investigate if and how effects differ depending on whether people are on the favorable or unfavorable side of a market. We achieve this by using the so-called box-design of a market that involves a long and a short side of the market with inelastic supply and demand curves (Holt et al., 1986). This market configuration implies that individuals on one side of the market will easily make transactions at favorable prices, whereas individuals on the other side of the market will have difficulties to make transactions and will do so at unfavorable prices, if they transact at all.

This feature represents in a stark way the very unequal opportunities that exist in some market economies or market segments (e.g., labor markets for high and low skilled workers). ${ }^{3}$ It will also give rise to endogenous earnings differentials among agents. Thus, there will be market-winners with high earnings from market interactions and market-losers with low earnings. Our main interest is in how different market experiences affect behavior in a social dilemma game keeping everything else equal. We therefore control for earnings differences as explained further below.

The second dimension of market experience we investigate relates to whether people have to overcome the social dilemma problem together with people with whom they have had or have not had a joint market experience. In the experiment we can study this by immersing participants into the same competitive market environment but matching them for the social dilemma exogenously in a way that ensures that they do or do not share a common market experience.

The social dilemma we investigate is a repeated two-person public goods game in which pairs are fixed throughout all periods (Chaudhuri, 2011; Kagel and Roth, 2012). Our design allows us to explore how, respectively, pairs of marketlosers, market-winners and mixed pairs (i.e, pairs consisting of a market-loser and a market-winner) are affected in their efficiency of cooperation. In addition, we vary whether pairings in the social dilemma game come from the same market or from different markets. For convenience we will refer to the former case as Market-Partners and the latter case as MarketStrangers. Finally, within the context of our experiment, we are not only interested in the immediate impact of market interaction on cooperation but also ask whether an eventual effect fades out, persists, or is reinforced over time, a distinction we will refer to with the labels 'short run' and 'long run', for ease of exposition.

Our study also relates to the broader issue of the influence of institutions on economic and social motivations, which still is an under-explored topic in economics (Fehr and Hoff, 2011). For instance, van Winden (2012) argues that to understand economic and social interactions one needs to take into account the existence and dynamics of social ties between people and how they are affected by the context in which these interactions take place. Bowles and Polania-Reyes (2012) present an extensive survey of the evidence documenting that social motivations are not necessarily separable from the environment and experiences related to the environment.

There are two prominent contrasting views pertaining to the potential spillover effects of markets on non-market activities requiring cooperation. Smith (1998) builds on Adam Smith to postulate that people intuitively know how to behave both in a cooperative and in a competitive way depending on the context. According to this view, both behaviors grow out of a universal propensity for social exchange which "finds expression in both personal exchange in small-group social transactions and in impersonal trade through large-group markets." (Smith, 1998, p.3) Smith sees cooperative and non-cooperative behavior as peacefully coexisting, with efficiency in impersonal markets being based on competitive behavior, while efficiency in personal social exchange requires the ability to find ways to engage with others to avoid free-riding. This view implies that market experience should not affect behavior outside the market.

Relatedly, Henrich et al. (2001) report correlational evidence suggesting that market interaction can have positive effects on cooperation. They find that "the higher the degree of market integration (...) the greater the level of cooperation in experimental games." (Henrich et al., 2001, p. 74) The rationale for this relation proposed by these authors is that "the more frequently people experience market transactions, the more they will also experience abstract sharing principles concerning behaviors towards strangers (...)." (Henrich et al., 2001, p. 76) This is consistent with the notion of doux commerce as put forward among others by Montesquieu (1748) already in the eighteenth century.

In contrast, Bowles (1998) suggests that market participation can adversely affect people's personality. Specifically, he argues that “(...) there are significant differences in the personality effects on participants in markets (...) for people on the

\footnotetext{
2 Needless to say that this does not imply that we consider other market institutions or other competitive environments to be uninteresting. However, being the first study exploring competitive market experience on non-market cooperation we chose an institution that (a) is undisputed in being a good reflection of decentralized market behavior and (b) does avoid potential confounds due to structural market imperfections and inefficiency (e.g., oligopolistic markets).

${ }^{3}$ Less stark representations of unequal market opportunities are conceivable. We consider our implementation as a starting point providing benchmark results for other 'less extreme' market inequalities.
} 
short side (...) and those on the long side of the market, some of which are simply excluded from the exchange process, while others fear losing the transactions they have secured." Bowles (1998, p. 78) concerns can be seen as part of the broader question asking whether market exchange erodes moral and civic goods worth preserving (Fourcade and Healy, 2007; Sandel, 2012; 2013). This view implies an adverse affect of market experience on the efficiency of cooperation outside the market, especially for market-losers.

A priori the diverging views on potential spillover effects of market participation are both reasonable and empirical evidence is necessary to ascertain their relative merit. If the negative spillover effects of market participation discussed by Bowles indeed depress the efficiency of voluntary cooperation this would be a major challenge for societies in which markets play a central role. ${ }^{4}$ However, as mentioned above, there are also reasons to believe that market participation is innocuous or is even beneficial for the efficiency of non-market interactions. With our study we want to contribute to shedding light on this important issue. To the best of our knowledge this is the first study doing this.

In the field non-market interactions are affected by a multitude of factors which makes it difficult to tease out the effect of market experience on the basis of field data. The use of laboratory experiments makes it possible to study spillover effects of market participation with a high degree of control under ceteris paribus conditions. Specifically, we are able to exogenously assign participants to the two sides of the market. Without laboratory control naturally more cooperative people might be over-represented on one or the other side. Similarly, we are able to control the composition of the groups in the subsequent social dilemma and, hence, study behavior for all possible matchings between participants with different market experiences. ${ }^{5}$

Our experimental set-up includes both market treatments and non-market treatments. We directly compare behavior in market treatments with that in non-market treatments. In the latter participants have no market experience and are endowed with earnings that are on average equal to the market earnings made by participants with market experience. This allows us to separate the effects of being a market-loser or market-winner from that of just having higher or lower earnings. As different market positions inevitably are associated with different earnings potentials, this separation would be virtually impossible with field data. In additional control treatments we test if it matters (a) whether or not participants are informed about (potentially) different earnings and (b) whether it makes a difference when agents have to work for their earnings instead of receiving them as windfall gains.

Our results show that market experience can affect the efficiency of cooperation outside the market and that the precise strength and direction of the spillover effect depends on specific market circumstances. For traders with a joint competitive market experience (Market-Partners) we find that the efficiency of cooperation decreases strongly for market-loser pairs and also, albeit to a lesser extent, for market-winner pairs. In contrast, in Market-Strangers, pairs of market-winners manage to cooperate more efficiently than comparable pairs without market experience but this holds only in the short run. Thus, having competed for scarce resources on the same side of the same market depresses efficiency in the social dilemma.

In two subsequently conducted treatments, we subject our Market-Partners results to additional scrutiny. First, we test if making fully transparent the earnings received before the social dilemma game affects the outcomes. Second, in a treatment that we pre-registered, we replaced the market that takes place before the social dilemma game by an individual real-effort task which yielded an experience parallel to that of the market. The results from these new treatments are similar to those of the original ones, albeit the significance levels tend to be weaker. This points to the possibility that, when adding features that define market interactions compared to non-market situations, cooperation behavior after having experienced these altered non-market situations may approach cooperation behavior after market experience.

In summary, our results comparing the treatment with market experience to the different control treatments indicate that the observed differences in the efficiency of cooperation cannot be solely explained by earnings differentials or by other differences that do not pertain to market interaction per se. Hence, we can attribute a substantial part of the cooperation differences in a causal sense to different market experiences in the cases we study. We note that with our experiment we cannot uniquely identify the mechanism behind our results. However, we can offer a tentative explanation of our main results in terms of direct competition weakening social ties, and of the more general notion of state-dependent preferences, in conjunction with a positive effect of advantageous market experience on the efficiency of cooperation. ${ }^{6}$

\section{Related experimental literature}

There are a number of related experimental papers studying the effect of competition on behavior in a variety of environments. None of them deals with how interaction in competitive markets under different circumstances affects subsequent efficiency in cooperation. The efficiency of markets-in the sense of the generation of economic surplus-is a central issue in economics. However, in case of spillover effects from markets to non-market interactions this may not reflect the overall

\footnotetext{
4 Our focus is on spillover effects on efficiency, because they are more directly economically relevant. However, spillover effects could also be on psychological dimensions like efficacy as captured in the Rotter score (see Rotter, 1966) or social dominance orientation (see Sidanius and Pratto, 2004).

5 Another advantage of lab experiments is the possibility of replication which allows for a systematic study of the relevant issues. See Falk and Heckman (2009) for a methodological discussion of the relevance of laboratory experiments in the economic and social sciences.

${ }^{6}$ For behavioral and neuronal evidence on the existence and dynamics of social ties even in the anonymous environment of laboratory experiments, see, e.g., Sonnemans et al. (2006) and Bault et al. (2015).
} 
efficiency effect of markets. Here we investigate how market experience under different circumstances affects after-market efficiency. We now briefly refer to some previous work and highlight the differences with our work.

Bauernschuster et al. (2013) use partner-choice games to study how competition between two investors interacts with trust and trustworthiness. In simple one-shot trust games they find that competition among trustors does not significantly increase sent amounts. However, trustees react to competition between trustors by lowering return ratios. Similarly, Huck et al. (2012) study a repeated binary trust game related to a market for an experience good with a fixed price where the buyer can choose whether to trust or not and the seller can only choose quality. Without competition, buyers are in each period randomly assigned to sellers. With competition, buyers choose in each period the seller from whom they want to buy. The authors report that the introduction of competition is highly effective, with efficiency rising from 30 to over $80 \%$.

Brandts et al. (2009) also use partner-choice games to study the effects of rivalry on the disposition towards others and on subjective well-being. They use a finitely repeated prisoner's dilemma game between fixed triads of players, where one of the three players can in each period choose with whom of the other two players to interact, leaving the third player without interaction. The results show that rivalry affects individuals differently, depending on which side of the rivalry they are on. It negatively affects experienced well-being of those on the powerless side of the interaction and has a positive effect for the powerful player leading to a larger inequality in experienced well-being. Interacting under rivalry also affects negatively the disposition towards others. Interestingly, the efficiency of cooperation is the same in conditions with and without rivalry.

Herz and Taubinsky (2018) use another partner-choice game to study how experience with competition shapes fairness standards. In their experiment participants first take part in ultimatum games with either proposer or responder competition and then play the standard ultimatum game. They find that responders' acceptance thresholds are higher for responders that started in the game with proposer competition than for those who started in the game with responder competition.

Partner-choice games as the ones used in the studies just mentioned involve an element of competition. However, in our view this kind of games do not adequately represent full-fledged market competition as the one we study, with both sides of the market participating actively and multiple transactions taking place.

Carpenter and Seki (2006) report on a field experiment conducted with three groups of workers from a fishing community in Japan, where the different groups were exposed to different amounts of competition on-the-job. The results show that these differences explain differences in cooperation in an experimental setting. Specifically, fishermen and fish wholesalers, who interact in more competitive environments are significantly less cooperative than staff who faces little competition on the job. This study is perhaps closest to our work, but does not speak directly to the issue of how the effects of market interaction can be distinguished from that of income differences. Moreover, the investigated on-the-job competition varies several variables simultaneously (e.g., intensity of competition and occupation), while we investigate the effect of competition on the efficiency of cooperation for agents who have been on either the long side or the short side of the market as well as for agents who have been on different market sides, keeping everything else equal. The mentioned study does also not speak to the effect of competition with strangers, which we investigate in one of our treatments. Lastly, as this study uses natural groups it cannot exclude selection effects.

Falk and Szech (2013) study behavior in a context in which market exchange can produce a negative externality - in their case the death of mice. They find that repeated market interaction typically yields less socially responsible behavior than one-shot non-market behavior. Bartling et al. (2015) present a comparison of social concern between Switzerland and China. They study behavior in both a non-market and a market context. They find that in both countries subjects exhibit less social concern in a market than in a non-market environment. In addition, they find that while there is no cross-country difference in behavior in a non-market context, in a market context social concern is lower in China than in Switzerland. ${ }^{7}$ Whether market participation makes one more disposed to subsequently hurt others is in our view different from the effects of subsequent cooperation efficiency and, in addition, in these studies the relevance of the specific conditions under which one participates in the market are not studied.

Two studies compare the effects of interacting under respectively, tournament and piece-rate incentives of subjects on Amazon Mechanical Turk on subsequent behavior. Buser and Dreber (2016) find that individuals are significantly less cooperative in a public goods game after having interacted under tournament incentives than under piece-rate. Chen (2011) compares the effects of interacting under competitive and piece-rate conditions on charitable donations and finds that a competitive environment leads to higher donations.

The focus and set-up of our study is quite different from the cited studies and complements important insights generated by this previous work. Our study reports the first causal evidence of different forms of competitive market experiences on the efficiency of cooperation controlling for the effects of differential earnings, which allows us to identify the effects of market interaction net of income effects. Specifically, we investigate the efficiency effects of experienced competition in markets with very unequal participation opportunities in which the experience of being on one or the other side of the

\footnotetext{
7 In a non-market context, Peysakhovich and Rand (2015) use a repeated prisoner's dilemma to study how being in environments that are conducive to cooperation lead to higher prosociality and trust in a subsequent one-shot situation than being in environments that do not support cooperation. The authors interpret this result in terms of the creation of habits of virtue.
} 
Table 1

Sequence of events in market treatments.

\begin{tabular}{lll}
\hline 1. & Self-assessment of subjective well-being & (SWB 1) \\
2. & Measurement of social value orientation & (SVO 1) \\
3. & Double auction market (18 periods) & (DAM) \\
4. & Social dilemma game (6 periods) & (SDG) \\
5. & Self-assessment of subjective well-being & (SWB 2) \\
6. & Measurement of social value orientation & (SVO 2) \\
7. & Surprise restart social dilemma game (12 periods) & (sSDG) \\
8. & Post-experiment questionnaire & \\
\hline
\end{tabular}

Note: SWB 1, SVO 1, SWB 2, and SVO 2 are described in detail in Online Appendix A.

market is vivid. ${ }^{8}$ In comparison to other studies we investigate factors typical for markets that have not been explored earlier. In particular, we can analyze the effect of asymmetric positions in the market (market-losers vs. market-winners) and the effect of more or less common experience of market competition (Market-Partners vs. Market-Strangers).

\section{Experiment design}

Our design has two main building blocks: (1) a highly competitive continuous double auction market (hereafter, DAM) and (2) a social dilemma game (hereafter, SDG). We implemented four main treatments: two market treatments in which the DAM is played before the SDG, and two non-market treatments, consisting of three conditions each, that control for earnings achieved in the market phase of the market treatments. All treatments also involve two measurements of subjective wellbeing (SWB) and of social value orientation (SVO). To keep the paper focused we describe the two main building blocks (DAM and SDG) in detail here but relegate the description of the SWB and SVO to Online Appendix A. In the following we first present the two market treatments followed by the two non-market treatments. ${ }^{9}$

\subsection{Market treatments}

Both market treatments consisted of eight parts. Table 1 shows the sequence of events. At the very beginning, participants were informed that the experiment would have several parts. Instructions for the various parts were given separately for each part, except those for parts 3 and 4 which were presented together. ${ }^{10}$

In part 1 (SWB 1) all participants had to answer a self-assessment question to measure their initial subjective well-being and in part 2 (SVO 1) they had to make money allocation decisions to measure their social value orientation. In part 3 (DAM) they interacted in 18 periods of the DAM and in part 4 (SDG) in six periods of the SDG. In parts 5 and 6 (SWB 2 and SVO 2, respectively) participants had again to self-assess their subjective well-being and make money allocation decisions to measure post interaction social value orientation. Part 7 (sSDG) consisted of a 'surprise' restart of the SDG, lasting for 12 periods. In part 8, participants answered questions about their individual characteristics. As mentioned above we focus on the description of the main building blocks of the experiment, that is Parts 3, 4, and 7.

Parts 3 and 4: DAM and SDG

To explore the potential effects of market experience on the efficiency of cooperation we wanted the SDG to start immediately after the markets closed. To achieve this, participants received the instructions for DAM and SDG together. This appears to be a more natural setting than the alternative where participants are ignorant of (potential) further interactions after having traded in a market. ${ }^{11}$ After having read the instructions and before the start of DAM participants had to answer comprehension questions about both DAM and SDG.

In each of the two market treatments participants interacted in the DAM for 18 periods and in each period there were the same three sellers and five buyers. Each seller was endowed with two units of a good which could be sold to the buyers and each buyer could buy up to two units. Thus, total market supply was six units and total market demand ten units, implying that buyers were on the long side of the market. We chose to give every trader two units (instead of only one) to create a thicker market with more trades without having to increase the number of traders. The production costs of each unit of the three sellers was 10 and the redemption value of each unit of the five buyers was 100 . This gives a so-called

\footnotetext{
8 A situation reminiscent of the notion of the reserve army of labor introduced by Engels (1987/1845). Some observers, see e.g., Standing (2011), consider that in modern globalized economies there now exists a new reserve army of labor, comprised of temporary and part-time workers, who lack any type of job security.

9 The experiment instructions can be found in Online Appendix D.

10 Sequentially presenting the different parts of the experiment involves an element of non-full immediate disclosure of information. Importantly, participants were informed beforehand that the experiment consisted of several parts and that for some parts they would receive detailed information only when the respective part starts. We used this structure because it avoids anticipation effects for the second SDG and in that way allows for a cleaner comparison between 'short run' and 'long run' effects of market interaction on the efficiency of cooperation.

11 Knowing that there will be a SDG after the market may have the potential to affect market behavior. However, the literature on double auction market experiments overwhelmingly shows that market forces wipe out other concerns (Davis and Holt, 1993). Our market results reported below corroborate these findings and do not suggest that the information given on the SDG has affected market behavior in a substantial way.
} 
box design with perfectly inelastic supply and demand (Holt et al., 1986). We chose that design because it creates distinct market experiences for agents on respectively the short and the long side of the market. Moreover, as traders on each side have identical market positions their behavior can be cleanly compared.

The earnings from the sale of a unit were equal to the price at which the unit was traded minus production costs of 10 , while the earnings from the purchase of a unit were equal to 100 minus the price at which the unit was traded. Not traded units created neither gains nor losses. The price was allowed to have any integer value between 10 and 95 (inclusive). We chose this upper bound on the trading price to break indifference and facilitate trade (Davis and Holt, 1993; Noussair and Tucker, 2013).

More formally, in each period the earnings of a buyer in the market were given by

$$
u= \begin{cases}\left(100-p_{x}\right)+\left(100-p_{y}\right) & \text { if the buyer buys one unit at price } p_{x} \\ \left(100-p_{z}\right) & \text { and another unit at price } p_{y} \\ 0 & \text { if the buyer buys one unit at price } p_{z} \\ \text { if the buyer does not buy any unit, }\end{cases}
$$

and the profit of a seller is given by

$$
\pi= \begin{cases}\left(p_{x}-10\right)+\left(p_{y}-10\right) & \text { if the seller sells one unit at price } p_{x} \\ \left(p_{z}-10\right) & \text { and another unit at price } p_{y} \\ 0 & \text { if the seller sells one unit at price } p_{z} \\ \text { if the seller does not sell any unit, }\end{cases}
$$

where $p_{x}, p_{y}, p_{z} \in\{10,11, \ldots, 94,95\}$.

The markets were anonymous and, depending on the market role, a trader knew her own production cost or redemption value, but did not know those of the other traders. Hence, traders did not receive information about the earnings of the other market participants. Participants were informed about the total number of buyers and sellers active in the market. We chose this information regime because it has been shown to minimize potentially confounding factors, like fairness considerations, and, thus, allows us to focus on the effects of market interaction per se. It also facilitates convergence to the competitive equilibrium (Smith, 1976; Holt et al., 1986) guaranteeing asymmetric market experience of buyers and sellers as intended. In the competitive equilibrium all six units are traded at price 95. Sellers' per unit equilibrium profit is 85 (95-10) and buyers' per unit equilibrium earnings are 5 (100-95).

In the DAM traders had to follow particular trading rules equivalent to those used in previous double-auction market experiments:

1. Buyers make purchase offers and sellers make sale offers. A purchase offer consists of a price at which to buy a unit. A sale offer consists of a price at which to sell a unit.

2. Only the highest purchase offer and the lowest sale offer are the so-called pending prices at which transactions can take place.

3. A transaction takes place automatically if the price of a purchase (sale) offer that is made is equal or higher (lower) than the price of the pending sale (purchase) offer. The transaction price is always the pending price, regardless of the offer that leads to the transaction. A transaction also takes place if a pending purchase (sale) offer is accepted by a seller (buyer).

4. New price offers have to be improvements. That is, a new purchase (sale) offer has to be higher (lower) than the pending purchase (sale) offer.

5. If a transaction takes place the market clears and any purchase offer or sale offer in the feasible price interval is possible again.

6. The units of the good are traded one by one. That is, traders cannot make offers for or trade several units at a time.

The DAM was conducted for 18 consecutive periods with the same fixed group of eight participants. Participants in a market did not know who they were matched with. A trading period ended after three minutes or when no trades were possible any more. All participants were informed about their role in the market, buyer or seller, at the beginning of the 18 periods of the DAM and were also told that these roles would stay constant throughout these periods. During the DAM buyers and sellers could see the purchase and sale offers and transaction prices but not the identities behind the offers and transactions. Hence, traders could not track others' individual behaviors across market periods. When a trade took place, traders received information only about their own earnings. At the end of a trading period each trader received information about his or her total earnings in that period.

Immediately, after the 18 periods of the DAM, participants played six periods of the SDG. The SDG was a two-person linear public goods game and pairs stayed the same throughout the game. In each period each participant was endowed with 50 ECU and had to distribute them between a private and a public account. We used an MPCR $=0.9$ so that for every unit that a player put into the public account both players in the pair obtained 0.9 units. ${ }^{12}$ Formally, in each period of the

\footnotetext{
12 The two-person version of the public goods game allowed us to obtain a relatively large number of independent observations at relatively low costs. The chosen MPCR was informed by pilot sessions with stand-alone two-person public goods experiments with the same subject pool as in the reported experiments. There we observed that an MPCR $=0.9$ lead to efficiency levels of about $50 \%$, leaving about the same room for efficiency improvement and worsening, respectively, in the market treatments.
} 


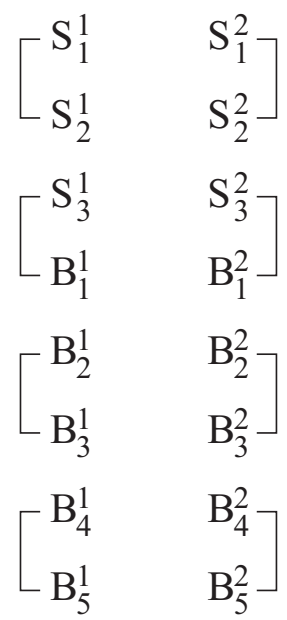

(a) Market-Partners
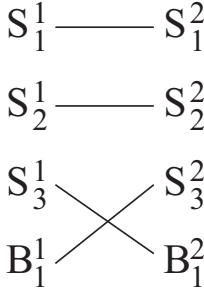

$\mathrm{B}_{2}^{1}-\mathrm{B}_{2}^{2}$

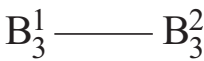

$\mathrm{B}_{4}^{1}-\mathrm{B}_{4}^{2}$

$\mathrm{B}_{5}^{1}-\mathrm{B}_{5}^{2}$

(b) Market-Strangers

Fig. 1. Matchings in the SDG in Market-Partners and Market-Strangers.

SDG, earnings of a participant $i$ were given by

$$
w_{i}=50-g_{i}+0.9\left(g_{1}+g_{2}\right),
$$

with $g_{i}(i=1,2)$ being player $i$ 's amount allocated to the public account. In the SDG, contribution decisions were made simultaneously. After each participant had made his/her decision each pair received information about decisions in their pair; that is, own contribution, other's contribution, own earnings, and other's earnings.

As already mentioned above, the matching in the SDG differed between the two market treatments, called MarketPartners and Market-Strangers. In the Market-Partners treatment each participant was matched with one of the other seven participants from the same DAM. Matching was done such that it led to two pairs of buyers, one pair of sellers and one pair consisting of a buyer and a seller. Specifically, the instructions specified: "You will be matched with another buyer (seller) with whom you have interacted in the market." Hence, in the SDG, participants knew the market role of the other participant they have been paired with. They were also told that they would stay matched with the same person during the six periods of the SDG. In this way we created two pairs of prospective market-losers (buyer pairs), one pair of prospective market-winners (seller pairs) and one pair consisting of a prospective market-loser and market-winner (mixed pairs).

In the Market-Strangers treatment each participant in a DAM was matched with one other participant from another DAM. Here the instructions specified: "You will be matched with another buyer (seller) from another market with whom you have not interacted in the market." In this case the matchings for the SDG were made using participants from two different DAMs. The sixteen subjects were matched in a way that led to four buyer-pairs, two seller-pairs, and two mixed pairs. Like in Market-Partners, market roles were known and the described matchings stayed the same for all periods of the SDG and participants were informed about this. Fig. 1 provides a graphical representation of the matchings in Market-Partners and Market-Strangers, respectively.

Part 7: sSDG

After the six periods of SDG 1 (and after SVO 2) a surprise restart of the SDG was announced and participants played an additional 12 periods of the SDG. Each participant was informed that they would be matched with the same person as in the first six periods. We introduced the surprise restart to check for persistence of any market experience effect and, for convenience, refer to this distinction as short run vs. long run. It allows us to see if effects on the efficiency of cooperation would be robust to a re-setting and longer lasting, an issue that is certainly relevant in market environments in the field.

\subsection{Non-market treatments}

As a benchmark to which to compare contribution behavior in the social dilemma game after the market interaction, we ran treatments where participants played a SDG without having experienced market interaction before. In these treatments, except for the absence of a DAM, the sequence of events was exactly the same as depicted in Table 1 . Like in the market treatments, each participant was matched with the same other person both in the first six and the second 12 periods of the SDG. We call these treatments OSDG (standing for 'Only' SDG). We have a treatment that is completely parallel to MarketPartners, which we will refer to as OSDG-MP, and one parallel to Market-Strangers, denoted by OSDG-MS.

A crucial feature of the OSDG treatments is that participants received initial lump-sum payments of money, which corresponded to the average earnings of participants in different conditions of the market treatments. As we will see in the results part, there are large earnings differences between sellers and buyers in the DAM. The initial lump-sum payments 
Table 2

Summary of market treatments and main non-market treatments.

\begin{tabular}{llllll}
\hline & Market-Partners & & \multicolumn{3}{c}{ Market-Strangers } \\
& $N=112$ & & & \\
& & & $n=192$ & \\
& $n=14$ & & & \\
Buyer pairs & Seller pairs & Mixed pairs & Buyer pairs & Seller pairs & Mixed pairs \\
$N_{b p}=28$ & $N_{s p}=14$ & $N_{m p}=14$ & $N_{b p}=48$ & $N_{s p}=24$ & $N_{m p}=24$ \\
$n_{b p}=14$ & $n_{s p}=14$ & $n_{m p}=14$ & $n_{b p}=12$ & $n_{s p}=12$ & $n_{m p}=12$ \\
& OSDG-MP & & & OSDG-MS & \\
& $N=72$ & & & $N=72$ & \\
& $n=36$ & & & $n=36$ & \\
'Buyer pairs' & 'Seller pairs' & 'Mixed pairs' & 'Buyer pairs' & 'Seller pairs' & 'Mixed pairs' \\
$N_{b p}=12$ & $N_{s p}=12$ & $N_{m p}=12$ & $N_{b p}=12$ & $N_{s p}=12$ & $N_{m p}=12$ \\
$n_{b p}=12$ & $n_{s p}=12$ & $n_{m p}=12$ & $n_{b p}=12$ & $n_{s p}=12$ & $n_{m p}=12$ \\
\hline
\end{tabular}

Note: $N(n) \ldots$ number of subjects (independent observations) on treatment level; $N_{x p}\left(n_{x p}\right) \ldots$ number of pairs (independent observations on pair level); 'buyer/seller/mixed pairs' indicates lump-sum payment condition mirroring buyer/seller/mixed pairs in the Market-Partners treatment and MarketStrangers treatment, respectively.

participants received were meant to control for potential effects of these differences on contribution behavior in the SDG. ${ }^{13}$ The use of a lab experiment makes it possible to control for income differences in this way and, hence, to isolate the effects of market participation net of earnings differences.

In each OSDG treatment, each participant was in one of two payment conditions. The conditions differed with respect to the received lump-sum payment, which corresponded respectively to the average buyer and seller earnings in MarketPartners and Market-Strangers. The instructions for the SDG in these benchmark treatments were kept as close as possible to those in the DAM. Regarding the lump-sum payments and the matching with another participant in the OSDG the instructions said: "You have been assigned initial earnings of $X$ ECU. The other group member is also assigned some initial earnings. The assignments to you and the other group member are not necessarily the same. You and the other group member will receive this amount independently of what occurs during the experiment." 14 We deliberately used a vague phrasing regarding the earnings of the other group member because in the DAM participants also only knew their own market earnings for sure. Market earnings of other traders could not be known because participants did not receive any information about traders' redemption values and production costs. ${ }^{15}$ We describe the exact lump-sum earnings and corresponding matchings in the OSDG treatments after we have discussed behavior in markets and thus know earnings from market interaction for all types of traders (see end of Section 6.1).

\section{Experiment procedures}

In total 448 subjects participated in the described main treatments of our experiment. ${ }^{16}$ We ran three sessions with the Market-Partners treatment, four with the Market-Strangers treatment and three with the OSDG treatments. We have data from 112 subjects in Market-Partners in 14 separate markets, 192 subjects in Market-Strangers in 24 separate markets, thus 12 interlinked markets, and 144 subjects in OSDG in 72 separate pairs. For Market-Partners we have 56 pairs in the SDG (28 buyer-pairs, 14 seller-pairs, 14 mixed-pairs) organized in 14 independent matching groups (markets) and for Market-Strangers we have 96 pairs in the SDG (48 buyer pairs, 24 seller pairs, 24 mixed pairs) organized in 12 independent matching groups (interlinked markets across which participants are matched in the subsequent SDG). In OSDG the 72 statistically independent observations (i.e., matched pairs of participants in the SDG) are distributed over six different lumpsum payment conditions with 12 independent pairs per condition. These lump-sum payment conditions mirror the buyer pairs, seller pairs, and mixed pairs in the Market-Partners and Market-Strangers treatment, respectively (see Section 6.2 for details). Table 2 provides an overview of the treatments, number of subjects, number of pairs in the SDG and number of independent observations in each treatment and pair, respectively.

In the two market treatments, each participant's role (buyer or seller) was fixed for the duration of the session. General instructions were read out aloud at the start of each session. Instructions for the different parts were given on-screen and

\footnotetext{
13 We chose to implement average earnings as lump-sum payments instead of the exact distributions of earnings for two reasons. First, because it highly simplifies the already complex design and, second, because within the set of buyers and sellers, respectively, earnings differences are relatively small (see Section 6.1 for average earnings and standard errors of earnings).

14 The actual amount $X$ of ECU used in the instructions depended on the condition the participant was assigned to (see Section 6.1 below).

15 It has been suggested to us that in the market treatments participants could use observed transaction prices and the dynamics of the market to infer something about the earnings of the other side of the market. We acknowledge that this is not impossible, but believe that the earnings information possibly extracted is too noisy to have a significant effect. Nevertheless, to check whether full transparency regarding the lump-sum income changes contributions in the SDG, we conducted an additional treatment that exactly matches the OSDG-MP but reveals the information about lump-sum incomes to both participants in a pair. For details and results, see Section 7.

16 In addition, respectively, 90 and 174 subjects participated in two additional non-market treatments (see, Section 7 ) giving a total of 712 participants.
} 
participants could read them at their own pace. ${ }^{17}$ Participants could ask questions by raising a hand. All questions were answered in private.

The experiments were conducted at the LINEEX lab at the University of Valencia using the z-tree program of Fischbacher (2007). Each session involved one of the treatments and no one could participate in more than one session. ${ }^{18}$ Performance-based earnings were counted in ECU and total earnings consisted of the accumulated earnings across all parts. Each 100 ECU were worth $€ 1$. Participants did not receive a show-up fee. At the end of a session participants were privately paid out their earnings in cash. Average earnings were $€ 33.00$ for OSDG and $€ 29.50$ for the market treatments. Non-market sessions took about 90 min and sessions with market treatments took about $120 \mathrm{~min}$.

\section{Research questions}

Our research questions relate directly to the views of Smith (1998) and Bowles (1998) presented in the Introduction and to the distinction between state-dependent preferences and separable preferences between economic incentives and social preferences introduced by Bowles and Polania-Reyes (2012). The notion of separability is also implied in the view proposed by Smith (1998) stating that people are able to decouple behavior in small-group exchange from that in anonymous markets. In the context of our experiment, separability means that the ability to efficiently cooperate in a social dilemma game is independent of preceding market experience.

Alternatively, behavior can depend on the circumstances surrounding the decision situation, which can be captured by the notion of state-dependence. ${ }^{19}$ In the words of Bowles and Polania-Reyes (2012): "State-dependence arises because actions are motivated by a heterogeneous repertoire of preferences from spiteful to payoff-maximizing to generous, for example, the salience of which depends on the nature of the decision situation" (p. 373). ${ }^{20}$ Applied to our research this implies that preferences and behavior could be state-dependent in the general sense that market experience affects subsequent cooperation. Moreover, the effect could be positive and increase cooperation, in accordance with the idea of doux commerce of Montesquieu (1748) or it could be negative, in line with the social criticism of Engels (1987/1845), and decrease subsequent cooperation.

As advanced in the Introduction, our focus is on (i) whether market interaction as such affects subsequent behavior and (ii) whether particular variations in the nature of the market interaction will lead to variations in the efficiency of cooperation. Our design makes it possible to make a number of specific comparisons of interest.

First, we can separately compare behavior of agents who competed with each other on the same market (MarketPartners) and behavior of agents who experienced market interaction on different markets (Market-Strangers) to the behavior in the corresponding OSDG treatments as well as compare Market-Strangers with Market-Partners as such. One may expect the different kinds of relations in the market to differentially affect participants' attitudes towards the subsequent interaction. In Market-Partners the experience of having competed with each other for scarce resources may on the one hand inject some sense of social closeness and thus increase cooperation, but on the other hand it may also induce a competitive state that could be detrimental to efficient cooperation. The Market-Strangers setting may create an atmosphere of more anonymity and disconnectedness and thereby decrease the motivation to cooperate. On the other hand, the observations of Henrich et al. (2001) and Henrich et al. (2004) discussed in the Introduction suggest that market experience with strangers may have a positive effect on cooperation. Thus, a priori, it is an open question whether market interaction leads to more or less efficient cooperation in Market-Partners and Market-Strangers, respectively. We summarize this thoughts in our first research question.

Research Question 1. (a) Does market experience in Market-Partners and Market-Strangers affect the efficiency of cooperation positively or negatively relative to the corresponding non-market treatments OSDG-MP and OSDG-MS? (b) Does the efficiency of cooperation differ between Market-Partners and Market-Strangers? (c) Are there differences between the short run and the long run?

Further, continuing with the separation between Market-Partners and Market-Strangers we can disaggregate and compare behavior in different matchings of participants who have been on opposite sides or the same side of the market. In the latter

\footnotetext{
17 The main reason for not reading out aloud all instructions was that this would have revealed information about the potential earnings of buyers and sellers in DAM, which we wanted to avoid.

18 The market sessions have been run in February, March and June 2012 and the non-market sessions in June 2015 . The reason for the relatively large time gap between sessions is that originally we had conducted a control treatment without any pre-SDG earnings. We were convinced by discussants in seminars that this was not the best control treatment as it does not control for the earnings differences generated in the market. The control treatments OSDG-MP and OSDG-MS take care of this issue. For completeness we note that a Kruskal-Wallis test across the first OSDG and the reported OSDG-MP and OSDG-MS does not detect a difference in contributions $(p \geq 0.6648)$.

19 Bowles and Polania-Reyes (2012) distinguish between state-dependent and endogenous preferences. In their framework, the term endogenous preferences is used in relation to processes with effects that persist in the long run, typically as the result of a process of cultural transmission. In the context of our study, the effects we focus on can be better captured in terms of state-dependence.

20 An example of how state-dependence could be incorporated into a formal model of social preferences is the general model of Charness and Rabin (2002). This two-person model has a more standard part with own and other's payoff and also incorporates a particular parameter that is said to be set to 1 when the decision-maker thinks that the counter-part is misbehaving while it is set to 0 when the counter-part is not misbehaving. The state is whether the counter-part is misbehaving or not and this gives rise to a repertoire of two different social preferences.
} 


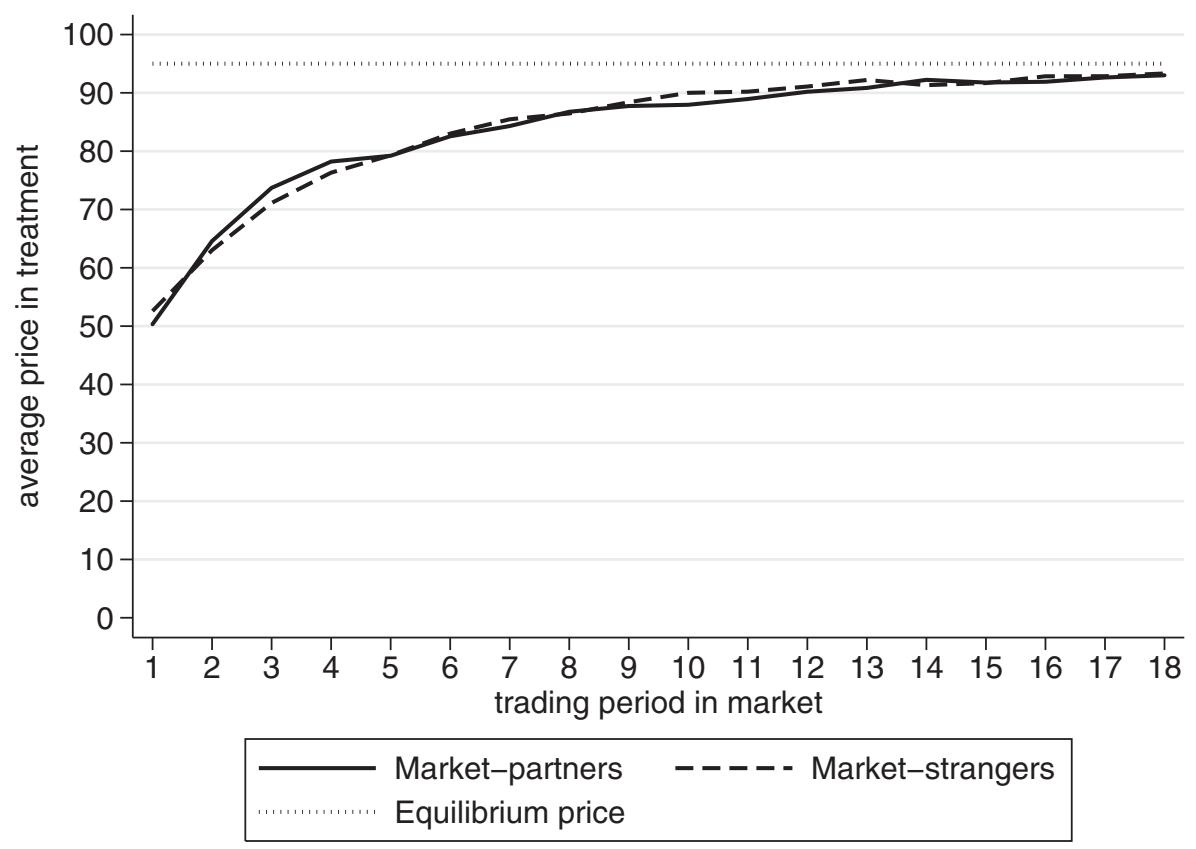

Fig. 2. Average trading price dynamics in both market treatments.

case we can also compare whether the market side itself matters. These comparisons are directly related to the potentially differential effects of experiencing market interaction on respectively the long and short side of markets, as mentioned in the citation from Bowles (1998) reproduced in the Introduction. They are of particular interest, because they touch on the important societal issue whether market experience has different repercussions for those who have it easy in the market (market-winners) compared to those who have a hard time (market-losers), although the term 'personality effects' may be too strong in the context of our experiment. These disaggregated comparisons will all be made with respect to the corresponding lump-sum payment conditions in OSDG-MP and OSDG-MS, respectively, so as to isolate the effect of market experience net of earnings differences. In addition, we can also make comparisons across market treatments to explore if the experience of being on respectively the long and short side of the market has differential effects in Market-Partners and Market-Strangers. This can be summarized in the following question.

Research Question 2. (a) Is the efficiency of cooperation of pairs of market-winners, market-losers and traders from opposite sides of the market affected equally, each compared with the corresponding case in the non-market treatments? (b) Does the efficiency of cooperation of these different pairs of traders depend on whether market interaction took place in Market-Partners or Market-Strangers? (c) Are there differences between the short run and the long run?

\section{Results}

In this section, we first briefly report on market behavior to see if our markets indeed converge to asymmetric equilibrium outcomes as intended. Thereafter, we zoom in to our research questions and discuss if and how different market experiences affect behavior in the subsequent social dilemma games. ${ }^{21}$

\subsection{Market behavior}

Fig. 2 shows the average transaction price over the 18 trading periods in the two market treatments. As expected, prices in both treatments converge to the highest possible price of 95 . Of the total of 4104 possible trades only 7 were not realized and overall efficiency was with $99.8 \%$ virtually optimal. Thus, markets clear, are efficient and lead to very unequal incomes. Using individual data, the averages (standard errors) of earnings are 2672 (st.dev.: 277, st.err.: 43) for sellers and 340 (st.dev.: 176, st.err.: 21) for buyers in the Market-Partners treatment and 2656 (st.dev.: 324, st.err.: 38) for sellers and 346 (st.dev.: 222, st.err.: 20) for buyers in the Market-Strangers treatment. ${ }^{22}$

\footnotetext{
${ }^{21}$ Results regarding the effect of different experiences in the markets and social dilemma games on subjective well-being and social value orientation can be found in Online Appendix C.

${ }^{22}$ Note that if there are any pre-existing social preferences they apparently have little effect on the outcome of the market interaction, due to the competitiveness of the institution (see Bolton and Ockenfels, 2000).
} 
Table 3

Efficiency of cooperation in market and non-market treatments (across trader matchings).

\begin{tabular}{|c|c|c|c|c|c|c|c|}
\hline \multirow[t]{2}{*}{ Treatment } & \multirow[t]{2}{*}{$N$} & \multicolumn{3}{|c|}{ Short run } & \multicolumn{3}{|c|}{ Long run } \\
\hline & & Median & Mean & St. dev. & Median & Mean & St. dev. \\
\hline Market-Partners & 14 & 23.740 & 23.025 & 7.556 & 26.120 & 22.172 & 7.502 \\
\hline OSDG-MP & 36 & 33.167 & 30.801 & 13.814 & 41.104 & 32.766 & 15.659 \\
\hline Market-Strangers & 12 & 32.146 & 31.418 & 3.154 & 31.357 & 30.422 & 3.612 \\
\hline OSDG-MS & 36 & 27.500 & 28.468 & 12.197 & 34.708 & 31.669 & 14.551 \\
\hline MP vs. OSDG-MP & & & $p=0.024^{* *}$ & & & $p=0.005^{* *}$ & \\
\hline MS vs. OSDG-MS & & & $p=0.205$ & & & $p=0.660$ & \\
\hline MP vs. MS & & & $p=0.006^{* *}$ & & & $p=0.001^{* * *}$ & \\
\hline
\end{tabular}

Note: all statistics and tests are based on strictly independent observations; $p$-values come from bootstrap two-sample $t$-tests, two-sided; $*^{* * *, * *, *}$ significant at least at the respectively, $1 \%$, $5 \%, 10 \%$ level with false discovery rate correction for multiple (six) comparisons (Benjamini and Hochberg, 1995); MP (MS) stands for Market-Partners (Market-Strangers).

As expected, neither buyer nor seller earnings significantly differ between Market-Partners and Market-Strangers (buyer earnings: $p=0.6434$, seller-earnings: $p=0.5371$; MW-tests, 2 -sided). We can conclude that our manipulation worked as intended. Thus, in both implemented market environments we achieved an efficient allocation of resources with very different market experiences for participants on the long and on the short side of the market.

Before moving on to the discussion if and how market experience affects the efficiency of cooperation we briefly explain how the different lump-sum payment conditions in the non-market treatments OSDG-MP and OSDG-MS were created. The idea was to match lump-sum (i.e., non-market) earnings of pairs of subjects in OSDG-MP and OSDG-MS with average earnings of buyer pairs, seller pairs and mixed pairs in Market-Partners and Market-Strangers, respectively. We have just seen that in Market-Partners sellers earned on average 2672 ECU and buyers 340 ECU. In Market-Strangers the corresponding earnings were $2656 \mathrm{ECU}$ and $346 \mathrm{ECU}$. To control for these income differences, in OSDG-MP and OSDG-MS we assigned participants to the following lump-sum earnings pairs: 340-340, 2672-2672, and 2672-340, respectively, to mimic buyer-buyer, seller-seller, and seller-buyer matchings in Market-Partners and 346-346, 2656-2656, 2656-346 to mimic the equivalent matchings in Market-Strangers.

\subsection{Efficiency of cooperation after market interaction}

In our presentation of results we use the research questions posed in Section 5 as a guide. We start with Research Question 1 where we look at potential effects of market experience per se in Market-Partners and Market-Strangers, respectively, and do not distinguish between different trader and lump-sum payment types. Table 3 shows descriptive statistics (medians, means, and standard deviations) for the efficiency of cooperation in the social dilemma game in Market-Partners, MarketStrangers, OSDG-MP, and OSDG-MS, respectively, as well as relevant bootstrap $t$-tests of differences between treatments. ${ }^{23}$ As explained above we also distinguish between the short run and the long run.

Focusing first on the Market-Partners treatment we see that contributions in Market-Partners are significantly lower than in the corresponding OSDG-MP. This holds for the short run $(p=0.024)$ as well as the long run $(p=0.005){ }^{24}$ Note that the average difference in the short run amounts to about $15.6 \%$ of the endowment (7.8 out of 50) and increases to about $21.2 \%$ of the endowment (10.6 out of 50 ) in the long run. The negative effect of market experience is thus also economically substantial. In contrast, there is no such negative effect in the Market-Strangers treatment, neither in the short run $(p=0.205)$ nor in the long run $(p=0.660)$. Finally, a comparison of Market-Partners with Market-Strangers shows that

\footnotetext{
${ }^{23}$ Unless indicated otherwise, all reported tests are two-sided bootstrap two-sample $t$-tests based on strictly independent observations (i.e., matched pairs in OSDG-MP and OSDG-MS, markets in Market-Partners, and interlinked markets in Market-Strangers). In the tables we report uncorrected $p$-values as well as significance levels corrected for multiple testing. For details, see the table notes. In Online Appendix B.1 we also provide non-parametric Mann-Whitney tests. The attained significance levels are largely the same as those provided here. In case of interesting differences we mention them in the text. We use bootstrap $t$-tests because $t$-tests also use the rich cardinal information contained in the data, whereas Mann-Whitney tests are based solely on the ordinality of the data. Applying the bootstrap technique allows us to conduct $t$-tests without making any assumptions about the distribution of the data. For a discussion of this method and the application to experiment data see, e.g., Moffat (2015).

${ }^{24}$ For ease of exposition, in the main text we refer to uncorrected $p$-values. In the tables we report significance levels after correction for multiple testing within a given research question. Alternatively, we could have corrected for all tests we have run or even for all tests we could have run, as suggested by an anonymous reviewer. In our view the question of correction for multiple hypotheses testing is an important one in order to increase the robustness of results (Camerer et al., 2016). A downside of correcting for multiple hypotheses testing is that it increases the likelihood of false negatives. Thus, one needs to find the subtle balance between being too liberal (false positives) and too conservative (false negatives). Unfortunately, there is no accepted gold standard for this balance and we believe that our approach is a reasonable compromise. We are aware of the fact that we may be low on statistical power for some of our tests, due to the many individual observations needed for a statistically independent observation in our market treatments. Correcting for more comparisons would likely lead to less statistically significant results and some of our results might be false positives. Therefore, as proposed by Maniadis et al. (2014) independent replications may be worthwhile to be undertaken.
} 
Table 4

Efficiency of cooperation in market treatments and non-market treatments for the different trader matchings.

\begin{tabular}{|c|c|c|c|c|c|c|c|}
\hline \multicolumn{8}{|l|}{ Buyer-buyer pairs } \\
\hline \multirow[t]{2}{*}{ Treatment } & \multirow[t]{2}{*}{$N$} & \multicolumn{3}{|l|}{ Short run } & \multicolumn{3}{|l|}{ Long run } \\
\hline & & Median & Mean & St. dev. & Median & Mean & St. dev. \\
\hline Market-Partners & 14 & 22.042 & 21.729 & 8.751 & 15.000 & 18.682 & 11.849 \\
\hline OSDG-MP (low-pay) & 12 & 33.542 & 34.243 & 9.633 & 41.104 & 33.038 & 15.326 \\
\hline Market-Strangers & 12 & 30.229 & 29.236 & 5.854 & 28.729 & 27.990 & 6.707 \\
\hline OSDG-MS (low-pay) & 12 & 33.125 & 32.597 & 9.083 & 35.875 & 33.674 & 13.375 \\
\hline MP vs. OSDG-MP & & & $p=0.003^{* *}$ & & & $p=0.039 *$ & \\
\hline MS vs. OSDG-MS & & & $p=0.311$ & & & $p=0.269$ & \\
\hline MP vs. MS & & & $p=0.018^{*}$ & & & $p=0.053^{*}$ & \\
\hline \multicolumn{8}{|l|}{ Seller-seller pairs } \\
\hline \multirow[t]{2}{*}{ Treatment } & \multirow[t]{2}{*}{$N$} & \multicolumn{3}{|l|}{ Short run } & \multicolumn{3}{|l|}{ Long run } \\
\hline & & Median & Mean & St. dev. & Median & Mean & $\overline{\text { St. dev. }}$ \\
\hline Market-Partners & 14 & 18.250 & 21.768 & 12.413 & 21.042 & 20.699 & 14.385 \\
\hline OSDG-MP (high-pay) & 12 & 26.500 & 29.097 & 15.536 & 38.521 & 34.222 & 15.634 \\
\hline Market-Strangers & 12 & 34.396 & 35.486 & 7.428 & 34.573 & 35.168 & 7.323 \\
\hline OSDG-MS (high-pay) & 12 & 23.833 & 23.785 & 11.064 & 33.917 & 31.649 & 14.522 \\
\hline MP vs. OSDG-MP & & & $p=0.249$ & & & $p=0.048^{*}$ & \\
\hline MS vs. OSDG-MS & & & $p=0.018^{* *}$ & & & $p=0.505$ & \\
\hline MP vs. MS & & & $p=0.020^{* *}$ & & & $p=0.012^{* *}$ & \\
\hline \multicolumn{8}{|l|}{ Buyer-seller pairs } \\
\hline \multirow[t]{2}{*}{ Treatment } & \multirow[t]{2}{*}{$N$} & \multicolumn{3}{|c|}{ Short run } & \multicolumn{3}{|c|}{ Long run } \\
\hline & & Median & Mean & St. dev. & Median & Mean & St. dev. \\
\hline Market-Partners & 14 & 27.125 & 26.875 & 15.507 & 34.167 & 30.625 & 16.213 \\
\hline OSDG-MP (mixed-pay) & 12 & 32.875 & 29.063 & 15.926 & 35.604 & 31.038 & 17.182 \\
\hline Market-Strangers & 12 & 29.271 & 31.715 & 7.368 & 28.563 & 30.540 & 9.051 \\
\hline OSDG-MS (mixed-pay) & 12 & 33.542 & 29.021 & 15.019 & 33.500 & 29.684 & 16.590 \\
\hline MP vs. OSDG-MP & & & $p=0.738$ & & & $p=0.953$ & \\
\hline MS vs. OSDG-MS & & & $p=0.597$ & & & $p=0.890$ & \\
\hline MP vs. MS & & & $p=0.356$ & & & $p=0.988$ & \\
\hline
\end{tabular}

Note: all statistics and tests are based on strictly independent observations; $p$-values are from bootstrap two-sample $t$-tests with 999 repetitions ( least at the, respectively, $1 \%, 5 \%, 10 \%$ level with false discovery rate correction for multiple (six) comparisons (Benjamini and Hochberg, 1995); MP (MS) stands for Market-Partners (MarketStrangers); in OSDG-MP and OSDG-MS 'low-pay' corresponds to income matchings 340-340 and 346-346, respectively, 'high-pay' to income matchings 2672-2672 and 2656-2656, respectively, and 'mixed-pay' to income matchings 340-2672 and 346-2656, respectively.

the efficiency of cooperation is substantially and significantly lower in the former than in the latter. Again this holds for the short and long run $(p=0.006$ and $p=0.001) .{ }^{25}$ We summarize in our first result.

Result 1. (i) Market experience strongly harms the efficiency of cooperation when traders have to solve the social dilemma with other traders they had previously interacted with in the same market. This holds in the short and in the long run and the negative effect tends to get larger in the long run. (ii) Market experience does not have a detrimental effect on the efficiency of cooperation when traders have to solve the social dilemma with other traders they did not interact with on the market before. This holds in both, the short and the long run.

Hence, across trader pairings, we find that market participation can be harmful for cooperation but find also that it is not harmful per se and that this pattern holds in the short run as well as the long run.

We next move to Research Question 2, whether the aggregate differences just discussed are similar for the different trader matchings or whether they are driven by specific matchings, and how this differs between Market-Partners and Market-Strangers. Recall that in buyer pairs the interacting participants both have had a difficult time in securing trades while in seller pairs participants have competed for trades from a relatively comfortable position. Finally, mixed pairs bring together very different market experiences. Table 4 reports descriptive statistics of contributions and corresponding tests for the three types of trader matchings, buyer-buyer, seller-seller and buyer-seller, in Market-Partners and Market-Strangers,

\footnotetext{
25 Regression analysis controlling for time trends and initial social value orientation (SVO 1) corroborates the test results reported here. In fact, the significance levels are stronger: the comparisons MP vs. OSDG-MP (long run) and MP vs. MS (short and long run) are significant at the 1\% level and MP vs. OSDG-MP (short run) at the 5\% level after false discovery rate correction for six pair-wise comparisons. For details, see Online Appendix B.2.
} 
respectively. The corresponding income matchings in OSDG-MP and OSDG-MS for convenience are called low-pay (340-340 and 346-346), high-pay (2672-2672 and 2656-2656), and mixed-pay (340-2672 and 346-2656).

Focusing on buyer-buyer pairs first we see that the pattern of contributions is the same as for the aggregate data shown in Table 3 above. Specifically, buyer-buyer pairs contribute less in Market-Partners than low-pay pairs in OSDG-MP, in the short run $(p=0.003)$ as well as in the long run $(p=0.039) .{ }^{26}$ Again the difference in average contributions between MarketPartners and OSDG-MP is economically substantial amounting to 25 and $28.6 \%$ of the endowment in the short run and in the long run, respectively. ${ }^{27}$ Also similar to the results across trader pairs, no such differences are found when comparing buyer-buyer pairs in Market-Strangers with low-pay pairs in OSDG-MS $(p \geq 0.311)$. Together this implies that buyer-buyer pairs in Market-Partners achieve significantly lower cooperation efficiency than buyer-buyer pairs in Market-Strangers, again in the short run $(p=0.018)$ as well as the long run $(p=0.053) .^{28}$

For seller-seller pairs in the Market-Partners treatment the contributions pattern is similar to the one observed for buyerbuyer pairs but appears to be less pronounced. Seller-seller pairs contribute less in Market-Partners than high-pay pairs in OSDG-MP in the short run as well as the long run, but the difference is statistically significant only in the latter case $(p=0.249$ and $p=0.048)$. Looking at the Market-Strangers treatment we see that seller pairs contribute more than highpay pairs in OSDG-MS. Now the difference is significant in the short run $(p=0.018)$ but not in the long run $(p=0.505)$. Finally, when comparing the two market treatments with each other we observe that the efficiency in Market-Partners is significantly and substantially lower than in Market-Strangers in the short $(p=0.020)$ and the long run $(p=0.006)$. Together this suggests that for seller-seller pairs there is some negative effect of experienced market interaction, but only when this interaction is in Market-Partners.

For mixed buyer-seller pairs there are no significant differences detected when comparing Market-Partners with OSDGMP, in the short run $(p=0.738)$ as well as the long run $(p=0.953)$, Market-Strangers with OSDG-MS (short run: $p=0.597$; long run: $p=0.890$ ), and Market-Partners with Market-Strangers (short run: $p=0.356$; long run: $p=0.988$ ). Thus, the efficiency of cooperation of traders who have been on opposite sides of the market is not hampered by market experience, irrespective of having interacted on the same or different markets. ${ }^{29,30}$ We summarize in our next result.

Result 2. (i) The observed overall adverse effects of market experience on the efficiency of cooperation in MarketPartners can be mainly attributed to market-loser pairs (buyer-buyer pairs) and, to a lesser extent, also market-winner pairs (seller-seller pairs). (ii) The efficiency of cooperation in Market-Strangers is unaffected for market-loser pairs and tends to be enhanced for market-winner pairs, in the short run. (iii) For both, market-loser and market-winner pairs, the efficiency of cooperation is lower in Market-Partners than in Market-Strangers. (iv) The efficiency of cooperation in trader pairs composed of market-winners and market-losers (buyer-seller pairs) is unaffected by previous market interaction.

The result that market experience has no effect whatsoever on traders who have been on opposite sides of markets (buyer-seller pairs) raises the question whether this is due to that both traders' contributions are unaffected or that one trader type contributes more while the other trader type contributes less. To test for this we looked at contributions of both types separately in the short run and the long run. In addition, as short run and long run levels may be affected by the dynamics of interaction, we also looked at contributions in the very first period of the first social dilemma game. Table 5 reports the results, which show that in buyer-seller pairs there is virtually no difference in contributions between buyers and sellers neither in the short nor in the long run. Also in period 1 the differences are small and statistically insignificant ( $p=1.000$ in Market-Partners and $p=0.4546$ in Market-Strangers). From that we conclude that market experience does not affect the efficiency of cooperation in groups consisting of a market-winner and a market-loser.

In Online Appendix B we also report comparisons of the efficiency of cooperation between different trader pairs within in each market treatment. The main result of these comparisons is that traders who have competed on the same market (i.e., in Market-Partners) and on the same side of the market-either on the favorable side (seller-seller pairs) or on the

\footnotetext{
${ }^{26}$ Interestingly, Mann-Whitney tests show even stronger significance results with $p=0.0040$ in the short run and $p=0.0139$ in the long run and both comparisons are significant at the $5 \%$ level after correction for multiple comparisons. See Online Appendix B.1 for details.

27 Cárdenas et al. (2014) report on a somewhat related result in a field experiment. Using an ultimatum game, they find that ex-combatants (losers in the armed conflict) expect to and actually receive lower transfers from public officers and citizens than victims and control groups.

${ }^{28}$ Again, Mann-Whitney tests tend to produce stronger significance results. In particular, after correction for multiple comparisons, the difference between Market-Partners and Market-Strangers remains significant at the 5\% level. See Online Appendix B.1 for details.

${ }^{29}$ All test results reported her are corroborated by Tobit regression analyses where we control for initial social value orientation (SVO 1) and period effects with period dummies. Again, significance levels tend to be stronger using regression analyses: after false discovery rate correction for six pair-wise comparisons, for buyer-buyer pairings all comparisons that are significant at at least the $10 \%$ level in Table 4 are significant at the $5 \%$ level, for seller-seller pairs all comparisons that are significant at the 5\% (10\%) level in Table 4 are significant at the $1 \%(5 \%)$ level. For details see Tables B.8-B.17 in Online Appendix B.2.

${ }^{30}$ When taking the very conservative statistical approach and correcting for all 18 comparisons reported in Table 4 we find that the following comparisons remain significant at the 10\% level: MP vs. OSDG-MP for buyer-buyer pairs in the short run, MS vs. OSDG-MS for seller-seller pairs in the short run, MP vs. MS for seller-seller pairs in both the short and the long run, and MP vs. MS for buyer-buyer pairs in the short run. Of these comparisons, for buyerbuyer pairs MP vs. OSDG-MP (short run) and for seller-seller pairs MP vs. MS (long run) just miss to reach significance at the $5 \%$ level. In addition, the comparisons of MP vs. OSDG-MP and MS vs. OSDG-MS in the short run just miss to reach significance at the $10 \%$ level. Again, when using Mann-Whitney rank sum tests stronger significance results are achieved. With these tests for buyer-buyer pairs the comparisons MP vs. OSDG-MP in the short and long run are significant at the $5 \%$ level and for seller-seller pairs this is the case for the comparisons MS vs. OSDG-MS in the short run and MP vs. MS in both the short and long run.
} 
Table 5

Contributions of buyers and sellers within buyer-seller matchings in market treatments.

\begin{tabular}{|c|c|c|c|c|c|c|}
\hline \multirow[t]{2}{*}{ Treatment and role } & \multicolumn{2}{|c|}{ Period 1} & \multicolumn{2}{|c|}{ Short run } & \multicolumn{2}{|c|}{ Long run } \\
\hline & Mean & St. dev. & Mean & St. dev. & Mean & St. dev. \\
\hline \multicolumn{7}{|l|}{ Market-Partners } \\
\hline Seller & 32.500 & 18.989 & 27.357 & 17.176 & 31.155 & 15.758 \\
\hline Buyer & 33.286 & 15.529 & 26.393 & 14.135 & 30.095 & 17.076 \\
\hline \multicolumn{7}{|l|}{ Market-Strangers } \\
\hline Seller & 34.917 & 14.163 & 30.757 & 8.582 & 29.615 & 9.282 \\
\hline Buyer & 37.292 & 15.250 & 32.674 & 7.329 & 31.465 & 9.580 \\
\hline
\end{tabular}

Note: 'Period1' statistics are based on individual observations $(N=14$ in Market-Partners, $N=24$ in Market-Strangers); 'Short run' and 'Long run' statistics are based on strictly independent observations ( $N=14$ in Market-Partners, $N=12$ in Market-Strangers).

unfavorable one (buyer-buyer pairs)-achieve less efficient cooperation outcomes than pairs of traders who also have been in the same market but on opposite sides of it (buyer-seller pairs). By contrast, for Market-Strangers having been on the favorable side of the market causes higher subsequent cooperation levels than having been on the unfavorable side. Thus, having competed on the same side on a market induces cooperation losses, whereas there seems to be a market-winner cooperation rent, which can however only be "cashed in" when the cooperation problem occurs with others who have not been in the same market.

\section{Additional control treatments and discussion}

In the previous section we have seen that relative to our control treatments market interaction has a negative effect in Market-Partners, especially for buyer-buyer pairs, a less strong and only long-run effect for seller-seller pairs, and no effect for mixed buyer-seller pairs. Moreover, in Market-Strangers no adverse effects of market interaction have been detected.

In this section we check and discuss the robustness of the results in Market-Partners by presenting the results of two additional treatments without market interaction and comparing them to Market-Partners for all three trader matchings. First, recall that in the market treatments, sellers' production costs and buyers' redemption values were private information making it difficult for participants to infer the market earnings of other buyers and sellers, respectively. Accordingly, in our OSDG treatments participants received only vague information about the lump-sum payments of other participants (see Section 3.2 for details). However, it is conceivable that in the market treatments participants could have used observed transaction prices and trading dynamics to infer something about the earnings of the other traders, especially of the opposite side. To control for this we ran an additional OSDG with income transparency. This treatment was exactly the same as the OSDG-MP except that the lump-sum payments within each pair of participants interacting in the social dilemma game was made transparent when the instructions for the SDG were given. This treatment is labeled OSDG-MP-T.

In this treatment we collected data from 90 participants who did not participate in any of the sessions reported above. ${ }^{31}$ As in OSDG-MP participants were partitioned into three sets of pairs with lump-sum income pairs of 340-340, 2672-2672, and 340-2672, respectively, giving 15 independent observations on the pair level.

Second, we conducted another treatment, called OSDG-MP-RE, where RE stands for real effort. This treatment was exactly the same as the OSDG-MP, except for the novel feature that the social dilemma game was preceded by an individual realeffort task in which participants had to earn their lump-sum income. The motivation for this treatment was to design an environment which had the main features of the market treatments, but without market interaction. ${ }^{32}$

The real effort task consisted of 18 periods each lasting for $95 \mathrm{~s}$, which was the average length of the 18 market periods in the Market-Partners treatment. This ensured that the time participants spent in the lab before the SDG was the same as in Market-Partners. In each of these periods participants faced the task of adjusting six sliders in the well-known slider task of Gill and Prowse (2012). Each correctly adjusted slider yielded a number of points. In the task participants were randomly assigned one of two exchange rates of correctly adjusted sliders into experimental currency units (ECU) which were valid for all 18 periods. Participants were informed of their exchange rate before the start of the slider task. One exchange rate was such that if a participant adjusted correctly all sliders in all periods, the participant would at the end of the 18 periods have earned an endowment equal to the average earnings of buyers in the Market-Partners treatment. The other exchange rate was such that if a participant correctly adjusted all sliders in all periods, the participant would at the end of the 18 periods have earned an endowment equal to the average earnings of sellers in the Market-Partners treatment.

\footnotetext{
31 In total we conducted three sessions at LINEEX in December 2016. A session lasted between 65 and 70 min with average earnings amounting to $€ 32,80$.

32 We thank an anonymous reviewer who pointed out the importance of controlling for these features. For this treatment, we conducted in total three sessions at LINEEX in December 2018. A session lasted about $120 \mathrm{~min}$ with average earnings amounting to about $€$ 32,-
} 
We calibrated the difficulty of the slider task so that all participants indeed earned an endowment equal to those used in the OSDG-MP treatment. ${ }^{33}$

Participants were informed that in the SDG they were paired with another participant who did exactly the same real effort task. In pairs resembling buyer-buyer (seller-seller) matchings, participants who earned 346 ECU (2672) ECU were informed that they are paired with another participant who had the same exchange rate in the real effort task. In pairs resembling buyer-seller matchings, participants with a low (high) exchange rate in the real effort task were informed that they were paired with another participant who had a superior (inferior) exchange rate. Participants were not informed about the actual performance and thus earnings of their paired participant. In this way we keep the information about others earnings similar to what participants could reasonably deduce from trading behavior in the markets of the MarketPartners treatment. For convenience, we will refer to the different pairings in this treatment also as respectively low-pay, high-pay, and mixed-pay pairings.

Summarizing, in the OSDG-MP-T treatment (as in OSDG-MP) participants received either the buyer endowment or the seller endowment as a lump-sum payment. The difference between treatments is that in the OSDG-MP-T participants receive exact information about the earnings of their paired counterpart in the SDG. This treatment thus controls for information on the lump-sum earnings. In the OSDG-MP-RE treatment, the information on pre-SDG payments is similar to OSDG-MP but in contrast to the original control treatment participants had to exert effort to receive these earnings. This treatment controls for several aspects also present in the Market-Partners treatment. First, as in the market, participants have to exert effort to receive payments, second, the time spent in the experiment prior to the SDG is exactly the same as in Market-Partners, third, although not interacting, participants know that the other participants are also engaged in the same real effort task and, fourth, participants with low (high) exchange rates are exposed to repeated low (high) earnings and, presumably related frustration (elation) as buyers (sellers) in the markets. Thus, this treatment controls for a number of aspects that arguably are not unique to market interactions, although these aspects are inevitably linked with interaction on our markets.

We note that the OSDG-MP-RE treatment was pre-registered at the AEA registry with the following explicit directed hypotheses, which were guided by Result 2 above:

Hypothesis 1. (a) Contributions in the buyer-buyer pairings are lower than contributions in the low-pay pairings. (b) Contributions in the seller-seller pairings are (weakly) lower than contributions in the high-pay pairings. (c) Contributions in the buyer-seller pairings are equal to contributions in the mixed-pay pairings.

To get a first impression on how the efficiency of cooperation for the three pairings differs across treatments, Fig. 3 shows average contributions for all treatments under consideration (Market-Partners, OSDG-MP, OSDG-MP-T, OSDG-MP-RE) in the short and the long run. There are several interesting observations to be made. First, for low-pay pairs (panel (a)) we see that for all three OSDG treatments contributions are higher than in Market-Partners, both in the short and the long run. There is also an interesting order within the OSDG treatments: contributions are highest in OSDG-MP and lowest in OSDG-MP-RE, with contribution in OSDG-MP-T being in-between. This order appears in the short and long run, although it is weaker in the latter case. Second, also for high-pay pairs (panel (b)) it holds that contributions are higher in all OSDG treatments than in Market-Partners, again both in the short and the long run. In contrast to low-pay pairs, however, there appears to be (almost) no difference across the three non-market treatments. Third, for mixed-pay pairs (panel (c)) there are few differences across all treatments, including the market treatment.

In the following we test for statistical differences in the efficiency of cooperation between Market-Partners and each of the two additional treatments separately. We base our directed hypotheses on the results observed in the previous section. That is, we test if the efficiency of cooperation is smaller in Market-Partners than in OSDG-MP-T and OSDG-MP-RE, respectively, for buyer-buyer vs. low-pay pairs and seller-seller vs. high-pay pairs. Additionally, we test the undirected hypothesis that for buyer-seller vs. mixed-pay pairs, the efficiency of cooperation does not differ between Market-Partners and, respectively, OSDG-MP-T and OSDG-MP-RE.

Table 6 reports descriptive statistics of the two new treatments together with the descriptive statistics of Market-Partners, for convenience. It also reports the appropriate test statistics. ${ }^{34}$ The table reports uncorrected $p$-values as well as significance levels after correcting for multiple comparisons within pairings using the false-discovery rate procedure. One can see that for buyer-buyer and seller-seller pairs, contributions in both OSDG-MP-T and OSDG-MP-RE are significantly higher than in Market-Partners, both in the short run and the long run at varying degrees of significance. By contrast, for buyer-seller pairs there are no significant differences between the treatments. For the OSDG-MP-RE the results are consistent with our Hypotheses $1(\mathrm{a})-1(\mathrm{c})$ above, at significance levels varying between $5 \%$ and $10 \%$ (uncorrected and corrected).

Summarizing the information presented in this section, the statistics shown in Table 6 are consistent with the notion that market experience leads to a decrease in the efficiency of cooperation in the SDG for participants who competed on the same side of the market but not for participants who competed on the opposite sides of the market. In addition, the order of average contribution levels shown in Fig. 3 and the (partly) weaker significance levels for OSDG-MP-T and

\footnotetext{
${ }^{33}$ The slider task was calibrated such that half of the participants earn 340 ECU and the other half 2672 ECU. Only one participant did not achieve this and earned 2647 ECU instead of the intended $2672 \mathrm{ECU}$. As the difference is minor and occurred in an early period, we do not exclude data of this participant.

${ }^{34}$ All reported test results are corroborated by Tobit regression analyses (see Online Appendix B.2).
} 


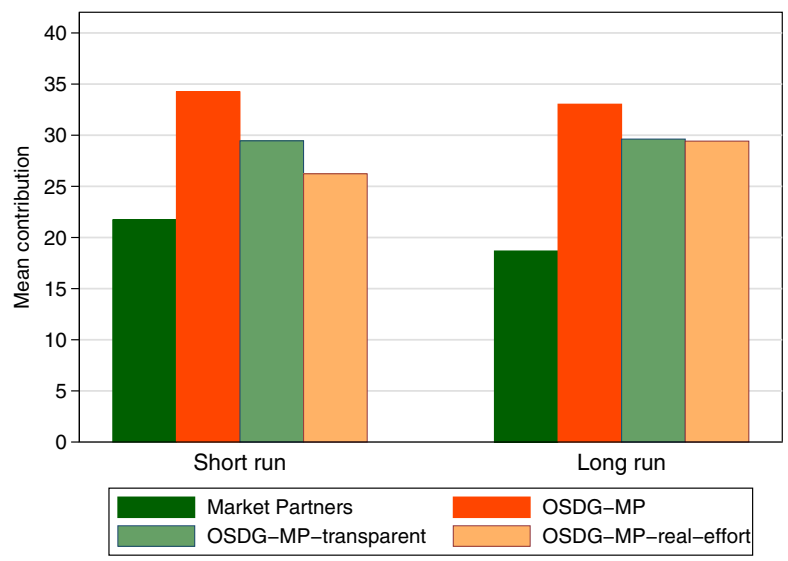

(a) Buyer-buyer \& low-pay pairs

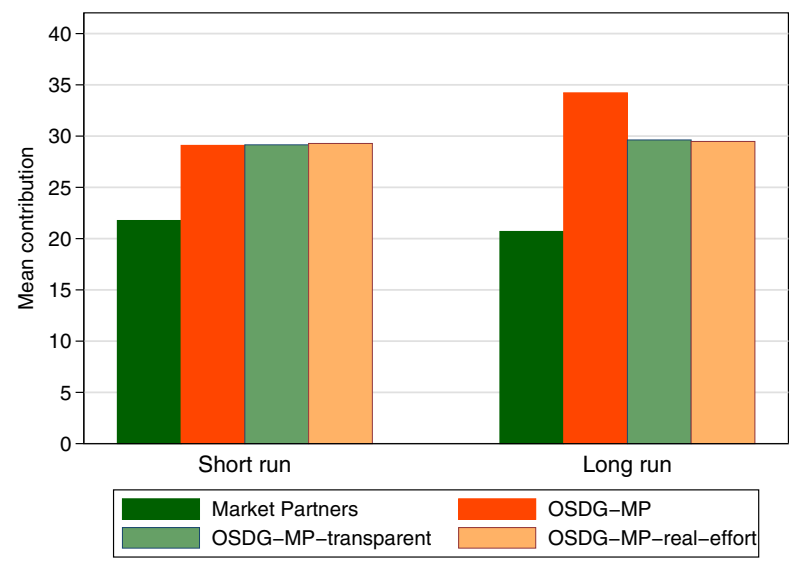

(b) Seller-seller \& high pay pairs

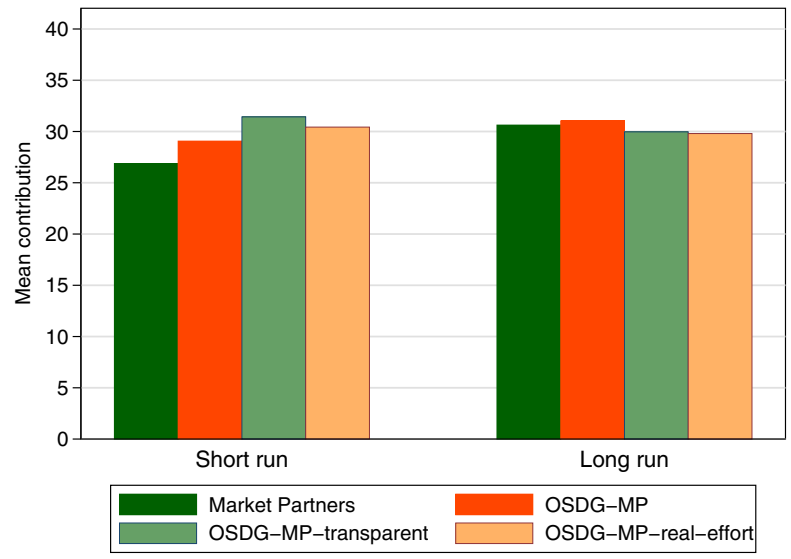

(c) Buyer-seller \& mix-pay pairs

Fig. 3. Efficiency of cooperation in different treatments for different trader pairs.

OSDG-MP-RE in comparison to OSDG-MP, suggest that incorporating dimensions that can be viewed as being typical for market experience into a non-market environment leads to lower cooperation.

\section{Summary and conclusions}

We have studied whether the experience of interacting in a competitive market affects the efficiency of cooperation in a subsequent social dilemma game played in pairs. In the markets trade takes place in real time and there is a short and a long side of the market. Participants on the short side have, compared to those on the long side, a strong competitive disadvantage and it is hard for them to secure transactions. Our experimental design allows us to compare the efficiency of cooperation with and without previous market experience, holding earnings constant. We can therefore isolate the causal effect of market experience, decoupled from the effect of the earnings inequality produced in markets. In addition, we can compare the effect of market experience on the efficiency of cooperation for participants who competed on the same market with participants who had a comparable market experience but competed on different markets.

The overall picture that emerges from our experiments has many nuances. Market experience can affect cooperation negatively but it is neither market experience per se nor being on the long or short side of the market per se that is adverse to efficient cooperation. It is the fact of having competed with each other in the same market and on the same side that makes subsequent cooperation difficult, with the impact being clearer for market-losers than for market-winners. Moreover, market experience can have in the short run a positive effect for those in an advantageous market position (market-winners) but only when the social dilemma needs to be solved with somebody who has been on a different market before. The latter 
Table 6

Efficiency of cooperation in Market-Partners treatment and OSDG-T and OSDG-RE for the different trader matchings.

\begin{tabular}{|c|c|c|c|c|c|c|c|}
\hline \multicolumn{8}{|l|}{ Buyer-buyer pairs } \\
\hline \multirow[b]{2}{*}{ Treatment } & \multirow[b]{2}{*}{$N$} & \multicolumn{3}{|l|}{ Short run } & \multicolumn{3}{|l|}{ Long run } \\
\hline & & Median & Mean & St. dev. & Median & Mean & St. dev. \\
\hline Market-Partners & 14 & 22.042 & 21.729 & 8.751 & 15.000 & 18.682 & 11.849 \\
\hline OSDG-MP-T (low-pay) & 15 & 28.333 & 29.450 & 16.268 & 35.833 & 29.622 & 20.295 \\
\hline OSDG-MP-RE (low-pay) & 29 & 26.250 & 26.230 & 13.485 & 27.792 & 29.424 & 14.387 \\
\hline MP vs. OSDG-MP-T ${ }^{1}$ & & & $p=0.066^{*}$ & & & $p=0.058^{*}$ & \\
\hline MP vs. OSDG-MP-RE ${ }^{1}$ & & & $p=0.093^{*}$ & & & $p=0.011^{* *}$ & \\
\hline \multicolumn{8}{|l|}{ Seller-seller pairs } \\
\hline & & \multicolumn{3}{|l|}{ Short run } & \multicolumn{3}{|l|}{ Long run } \\
\hline Treatment & $N$ & Median & Mean & St. dev. & Median & Mean & St. dev. \\
\hline Market-Partners & 14 & 18.250 & 21.768 & 12.413 & 21.042 & 20.699 & 14.385 \\
\hline OSDG-MP-T (high-pay) & 15 & 23.083 & 29.150 & 13.767 & 28.125 & 29.625 & 15.679 \\
\hline OSDG-MP-RE (high-pay) & 29 & 27.917 & 29.282 & 14.221 & 32.958 & 29.480 & 18.207 \\
\hline MP vs. OSDG-MP-T ${ }^{1}$ & & & $p=0.082^{*}$ & & & $p=0.070^{*}$ & \\
\hline MP vs. OSDG-MP-RE ${ }^{1}$ & & & $p=0.049^{*}$ & & & $p=0.052^{*}$ & \\
\hline \multicolumn{8}{|l|}{ Buyer-seller pairs } \\
\hline & & \multicolumn{3}{|c|}{ Short run } & \multicolumn{3}{|c|}{ Long run } \\
\hline Treatment & $N$ & Median & Mean & St. dev. & Median & Mean & St. dev. \\
\hline Market-Partners & 14 & 27.125 & 26.875 & 15.507 & 34.167 & 30.625 & 16.213 \\
\hline OSDG-MP-T (mixed-pay) & 15 & 29.833 & 31.428 & 17.155 & 39.125 & 29.967 & 19.162 \\
\hline OSDG-MP-RE (mixed-pay) & 29 & 30.417 & 30.431 & 12.592 & 28.958 & 29.802 & 16.251 \\
\hline MP vs. OSDG-MP-T² & & \multirow{2}{*}{\multicolumn{3}{|c|}{$\begin{array}{l}p=0.481 \\
p=0.485\end{array}$}} & \multicolumn{3}{|c|}{$p=0.925$} \\
\hline MP vs. OSDG-MP-RE ${ }^{2}$ & & & & & \multicolumn{3}{|c|}{$p=0.879$} \\
\hline
\end{tabular}

Note: all statistics and tests are based on strictly independent observations; $p$-values are from bootstrap two-sample $t$-tests with 999 repititions (seed $=713$ ), ${ }^{1(2)}$ one-(two-)sided; ${ }^{* * * * * * *}$ significant at least at the, respectively, 1\%, 5\%, 10\% level with false discovery rate correction for multiple (four) comparisons (Benjamini and Hochberg, 1995); MP (MS) stands for Market-Partners (MarketStrangers); in OSDG-MP-RE 'low-low' ('high-high') ['high-low'] corresponds to matchings with low (high) [mixed] exchange rates in the real effort task preceding the SDG.

is consistent with the correlational evidence reported in Henrich et al. (2001) and suggests that there exists a 'cooperation rent' for traders who are successful in markets, but only when the market interaction is with 'strangers'.

Our study can be of general interest for economists. The results show that competitive market experience can have significant and substantial spillover effects and impose economic costs (or, in some cases, benefits) in spheres of social interaction outside of the market. It is, of course, possible that the observed spillover effects would be smaller or even disappear in a market setting less extreme that the one we studied. Nevertheless, one can argue that market conditions like the ones in our experiment are representative for some 'naturally' occurring markets, as for instance, labor markets with high job insecurity. A more specific conclusion from our results could be drawn for the voluntary provision of (local) public goods. Namely, that people who are competing on a market with each other will be less likely to contribute to the local public good efficiently. Speculatively, this may provide an argument in favor of so-called 'social mixing' in urban planning (Uitermark, 2003; Lees, 2008): social mixing could increase local social capital because it decreases the likelihood that people who have to compete on the same side of the same market live in the same neighborhood.

We motivated our research questions using the framework of Bowles and Polania-Reyes (2012), who argue that preferences are state-dependent in the sense that "...actions are motivated by a repertoire of heterogeneous preferences the salience of which depends on the nature of the decision situation." (p. 372) The nature of the decision situation can also be affected by social experiences and different experiences can trigger different states. Our results may thus be understood in terms of state-dependent preferences. They are consistent with the notion that competitive market experience triggers a less cooperative preference state towards those one has directly competed with. This occurs regardless of whether one has competed with each other on the short or the long side of the market. The fact that this effect is also present for traders on the short side (market-winners) is quite remarkable. It highlights that the issue is not whether people have had competitive experience per se or have been successful in terms of income, but whether one has been in competition with each other or not.

Our observations call for a refinement of the concept of state-dependence. The question is why exactly certain types of market experience lead to less cooperation. One possible explanation is that direct competition per se damages affective social ties or may even lead to negative ties, while successful trades per se have a counterbalancing effect and may create or 
strengthen ties (for evidence on and the effects of social ties in the lab and the field, see, e.g., van Dijk and vanWinden, 1997; van Winden, 2012; Bault et al., 2015). This may explain why competition on the same market appears to be harmful for cooperation while this is not the case when this competitive experience was with somebody else. It is also consistent with the idea that a competitive seller-buyer relation even when it is asymmetric does not damage or even enhance affective ties between the traders (cf. the doux commerce idea of Montesquieu, 1748).

Another potentially important channel could work through how people's beliefs about others' cooperation are affected by market experience of different kinds. The result that cooperation rates of buyers and sellers in mixed pairs do not differ in the first period of the SDG suggests that differences in beliefs are not a main driving force of cooperation behavior. However, this evidence is only indirect and certainly not conclusive. The investigation of the precise role of beliefs and possible other mechanisms behind our behavioral results could be an exciting future research avenue.

Lastly we note that our results do not imply that competition other than competitive market interaction would not affect subsequent behavior. In fact, some of the studies cited in the literature section show that non-market competition can affect cooperation. In this paper we studied a kind of market competition that is of special interest given the societal relevance of such markets. Nevertheless, future research could address the question if an environment where participants compete against each other in a non-market environment (probably with non-monetary rewards) would affect subsequent cooperation in a social dilemma similarly to what we find in our market environments.

\section{Acknowledgment}

The authors thank the Spanish Ministry of Economics and Competitiveness through grant ECO2014-59302-P and through the Severo Ochoa Program for Centers of Excellence in R\&D (SEV2015-0563), the Generalitat de Catalunya (Grant: 2014 SGR 510) and the Antoni Serra Ramoneda Research Chair (UAB-Catalunya Caixa) for financial support.

\section{Supplementary materials}

Supplementary material associated with this article can be found, in the online version, at doi:10.1016/j.euroecorev.2019. 103318.

\section{References}

Bartling, B., Weber, R.A., Yao, L., 2015. Do markets erode social responsibility? O. J. Econ. 130 (1), 219-266.

Bauernschuster, S., Falck, O., Große, N., 2013. When trustors compete for the favour of a trustee - a laboratory experiment. J. Econ. Psychol. 34, 133-147.

Bault, N., Pelloux, B., Fahrenfort, J.J., Ridderinkhof, K.R., van Winden, F., 2015. Neural dynamics of social tie formation in economic decision-making. Soc. Cogn. Affect. Neurosci. 10, 877-884.

Benjamini, Y., Hochberg, Y., 1995. Controlling the false discovery rate: a practical and powerful approach to multiple testing. J. R. Stat. Soc. 57 (1), $289-300$. Bolton, G. Ockenfels, A., 2000. ERC: a theory of equity, reciprocity, and competition. Am. Econ. Rev, 90 (1), 166-193.

Bowles, S., 1998. Endogenous preferences: the cultural consequences of markets and other economic institutions. J. Econ. Lit. 36 (1), 75-111.

Bowles, S., Polania-Reyes, S., 2012. Economic incentives and social preferences: substitutes or complements? J. Econ. Lit. 50 (2), 368-425.

Brandts, J., Riedl, A., van Winden, F., 2009. Competitive rivalry, social disposition, and subjective well-being: an experiment. J. Public Econ. 93 (11/12), $1158-1167$.

Buser, T., Dreber, A., 2016. The flipside of comparative payment schemes. Manag. Sci. 62 (9), 2626-2638

Camerer, C.F., Dreber, A., Forsell, E., Ho, T.-H., Huber, J., Johannesson, M., Kirchler, M., Almenberg, J., Altmejd, A., Chan, T., Heikensten, E., Holzmeister, F., Imai, T., Isaksson, S., Nave, G., Pfeiffer, T., Razen, M., Wu, H., 2016. Evaluating replicability of laboratory experiments in economics. Science 351 (6280), $1433-1436$.

Cárdenas, J.C., Casas-Casas, A., Méndez, N., 2014. The hidden face of justice: fairness, discrimination and distribution in transitional justice processes. Peace Econ. Peace Sci. Public Policy 20 (1), 33-60.

Carpenter, J., Seki, E., 2006. Competitive work environments and social preferences: field experimental evidence from a japanese fishing community. Contrib. Econ. Anal. Policy, BE Press 5 (2). Article 2.

Charness, G., Rabin, M., 2002. Understanding social preferences with simple tests. Q. J. Econ. 117 (3), 817-869.

Chaudhuri, A., 2011. Sustaining cooperation in laboratory public goods experiments: a selective survey of the literature. Exp. Econ. 14 (1), 47-83.

Chen, D.L., 2011. Markets and morality: how does competition affect moral judgement? Working Paper.

Cowell, F.A., Van Kerm, P., 2015. Wealth inequality: a survey. J. Econ. Surv. 29 (4), 671-710.

Davis, D.D., Holt, C.A., 1993. Experimental economics. Chapter 3. Double-Auction Markets. Princeton University Press.

van Dijk, F., vanWinden, F., 1997. Dynamics of social ties and local public good provision. J. Public Econ. 64 (3), 323-341.

Engels, F., 1987/1845. The Condition of the Working Class in England. First published 1845, Germany, Penguin UK.

Falk, A., Heckman, J.J., 2009. Lab experiments are a major source of knowledge in the social sciences. Science 326 (5952), 535-538.

Falk, A., Szech, N., 2013. Morals and markets. Science 340 (6133), 707-711.

Fehr, E., Hoff, K., 2011. Tastes, castes and culture: the influence of society on preferences. Econ. J. 112 (556), 396-412.

Fischbacher, U., 2007. Z-tree: Zurich toolbox for ready-made economic experiments. Exp. Econ. 10 (2), 171-178.

Fourcade, M., Healy, K., 2007. Moral views of market society. Annu. Rev. Sociol. 33, 285-311.

Gill, D., Prowse, V., 2012. A structural analysis of disappointment aversion in a real effort competition. Am. Econ. Rev. 102 (1), 469-503.

Henrich, J., Boyd, R., Bowles, S., Camerer, C., Fehr, E., Gintis, H., 2004. Foundations of Human Sociality: Economic Experiments and Ethnographic Evidence from Fifteen Small-Scale Societies. Oxford University Press, Oxford, UK.

Henrich, J., Boyd, R., Bowles, S., Camerer, C., Fehr, E., Gintis, H., McElreath, R., 2001. In search of homo economicus: behavioral experiments in 15 small-scale societies. Ame. Econ. Rev. 91 (2), 72-78.

Herz, H., Taubinsky, D., 2018. What makes a price fair? An experimental of transaction experience and endogenous fairness views. J. Eur. Econ. Assoc. 16 (2), 316-352.

Holt, C.A., Langan, L., Villamil, A., 1986. Market power in oral double auctions. Econ. Inq. 24 (1), 107-123.

Huck, S., Lünser, G.K., Tyran, J.R., 2012. Competition fosters trust. Games Econ. Behav. 76 (1), 195-209.

Kagel, J.H., Roth, A.E., 2012. The Handbook of Experimental Economics, volume 2. Princeton University Press, Princeton, New Jersey. Forthcoming

Lees, L., 2008. Gentrification and social mixing: towards an inclusive urban renaissance? Urban Stud. 45 (12), 2449-2470. 
Maniadis, Z., Tufano, F., List, J.A., 2014. One swallow doesn't make a summer: new evidence on anchoring effects. Am. Econ. Rev. 104 (1), $277-290$. Marquis, M.H., Trehan, B., Tantivong, W., 2014. The wage premium puzzle and the quality of human capital. Int. Rev. Econ. Financ. 33, 100-110.

Mas-Colell, A., Whinston, M.D., Green, J.R., 1995. Microeconomic Theory. Oxford University Press, Oxford, UK.

Moffat, P.G., 2015. Experimetrics: Econometrics for Experimental Economics. Palgrave.

Montesquieu, C.B.d.S., 1748. The spirit of laws. Crowder, Wark, and Payne, 1777. Originally published anonymously. Trans. Thomas Nugent. 1750

Noussair, C.N., Tucker, S., 2013. A collection of surveys on market experiments. J. Econ. Surv. 27 (3), 395-397.

Peysakhovich, A., Rand, D.G., 2015. Habits of virtue: creating norms of cooperation and defection in the laboratory. Manag. Sci. 62 (3), 631-647.

Rotter, J.B., 1966. Generalized expectancies for internal versus external control of reinforcement. Psychol. Monogr.: Gen. Appl. 80 (1), 1.

Sandel, M.J., 2012. What Money Can't Buy: The Moral Limits of Markets. Farrar, Straus and Giroux, New York.

Sandel, M.J., 2013. Market reasoning as moral reasoning: why economists should re-engage with political philosophy. J. Econ. Perspect. 27 (4), 121-140.

Sidanius, J., Pratto, F., 2004. Social dominance theory: a new synthesis. In: Jost, J.T., Sidanius, J. (Eds.), Political psychology: Key readings. Key readings in Social Psychology. Psychology Press, New York, NY, pp. 315-332.

Smith, V., 1962. An experimental study of competitive market behavior. J. Polit. Econ. 70 (2), 111-137.

Smith, V., 1976. Experimental economics: induced value theory. Am. Econ. Rev. 66 (2), 274-279.

Smith, V., 1998. The two faces of Adam Smith. South. Econ. J. 65 (1), 1-19.

Sonnemans, J., van Dijk, F., van Winden, F., 2006. On the dynamics of social ties structures in groups. J. Econ. Psychol. 27 (2), $187-204$.

Standing, G., 2011. The Precariat; The Dangerous New Class. Bloomsbury Academic.

Uitermark, J., 2003. 'Social mixing' and the management of disadvantaged neighbourhoods: the dutch policy of urban restructuring revisited. Urban Stud. 40 (3), 531-549.

van Winden, F., 2012. Affective social ties-missing link in governance theory. Rational. Morals Mark. 3 (57), 108-122. 